\title{
Centrosome clustering and cyclin D1 gene amplification in double minutes are common events in chromosomal unstable bladder tumors
}

Javier del Rey ${ }^{1}$, Esther Prat ${ }^{1}$, Immaculada Ponsa ${ }^{1}$, Josep Lloreta ${ }^{2}$, Antoni Gelabert ${ }^{3}$, Ferran Algaba ${ }^{4}$, Jordi Camps ${ }^{1,5}$, Rosa Miró ${ }^{*}$

\begin{abstract}
Background: Aneuploidy, centrosome abnormalities and gene amplification are hallmarks of chromosome instability (CIN) in cancer. Yet there are no studies of the in vivo behavior of these phenomena within the same bladder tumor.

Methods: Twenty-one paraffin-embedded bladder tumors were analyzed by conventional comparative genome hybridization and fluorescence in situ hybridization (FISH) with a cyclin D1 gene (CCND1)/centromere 11 dual-color probe. Immunofluorescent staining of $\alpha, \beta$ and $\gamma$ tubulin was also performed.

Results: Based on the CIN index, defined as the percentage of cells not displaying the modal number for chromosome 11, tumors were classified as CIN-negative and CIN-positive. Fourteen out of 21 tumors were considered CIN-positive. All T1G3 tumors were included in the CIN-positive group whereas the majority of Ta samples were classified as CIN-negative tumors. Centrosome clustering was observed in six out of $12 \mathrm{CIN}$-positive tumors analyzed. CCND1 amplification in homogeneously staining regions was present in six out of 14 CIN-positive tumors; three of them also showed amplification of this gene in double minutes.

Conclusions: Complex in vivo behavior of CCND1 amplicon in bladder tumor cells has been demonstrated by accurate FISH analysis on paraffin-embedded tumors. Positive correlation between high heterogeneity, centrosome abnormalities and CCND1 amplification was found in T1G3 bladder carcinomas. This is the first study to provide insights into the coexistence of CCND1 amplification in homogeneously staining regions and double minutes in primary bladder tumors. It is noteworthy that those patients whose tumors showed double minutes had a significantly shorter overall survival rate $(p<0.001)$.
\end{abstract}

\section{Background}

Malignant tumors typically arise from multiple events within the developing cancer cells. Genetic damage is a hallmark of malignant cells and plays a key role in both the initiation and the progression of tumorigenesis [1].

Bladder cancer, along with most solid tumors, is characterized by multiple numerical and structural chromosome aberrations which in general associate with progression [2,3]. Amplification of 11q13 involving cyclin D1 gene (CCND1) is among the most common

\footnotetext{
* Correspondence: rosa.miro@uab.cat

'Departament de Biologia Cellular Fisiologia i Immunologia, Institut de Biotecnologia i de Biomedicina, Universitat Autònoma de Barcelona, 08193, Bellaterra, Spain
}

(C) 2010 del Rey et al; licensee BioMed Central Ltd. This is an Open Access article distributed under the terms of the Creative Commons Attribution License (http://creativecommons.org/licenses/by/2.0), which permits unrestricted use, distribution, and reproduction in any medium, provided the original work is properly cited. sites of gene amplification in T1-T2 high grade tumors [4-6]. Cyclin D1 plays an important role in cell cycle, binds to cyclin dependent kinases (CDK4/6), and promotes phosphorylation of RB1, orchestrating progression through the G1 restriction point.

Gene amplification involving oncogenes, a common mechanism to overexpress cancer-related genes, might be present in cancer cells as double-minute chromosomes (DMs) or homogeneously staining regions (HSRs). DMs are circular extrachromosomal autonomously-replicating DNA fragments lacking a centromere. HSRs are amplified intrachromosomal sequences that may be located in the same region of the amplified gene or in another chromosomal region [7]. The 11q13 
amplicon is generally located at the same chromosome region of the single-copy genes involved (CCND1, etc.) [8]; other amplifications, such as those involving $M Y C N$ in neuroblastomas, are inserted in several places in the genome other than chromosome 2, where $M Y C N$ gene is mapped $[9,10]$.

Numerical chromosome instability (CIN), which occurs very frequently in cancer cells [11], contributes to aneuploidy and plays a critical role in tumorigenesis as a key element of genomic instability $[11,12]$. Chromosome missegregation resulting from the deregulation of the spindle checkpoint is thought to be a potential cause of CIN. However, the molecular basis of this causative relation remains largely unknown [13]. The centrosome, a major microtubule-organizing center in animal cells, plays a vital role during mitosis as a spindle pole, and is crucial for accurate chromosome segregation to daughter cells [14]. In previous studies, centrosome amplification, defined as an increase in the centrosome number, has been identified in many different tumors, including bladder cancer $[15,16]$. In addition, centrosome amplification has been recently shown to initiate tumorigenesis in flies [17]. Several studies have demonstrated that centrosomal abnormalities and chromosome copy-number heterogeneity frequently coexist in bladder tumor cells [18-20]. More recently, Jin et al. [21] found that multipolar mitosis and anaphase bridges are common, often concurrent, mitotic abnormalities in urothelial carcinomas, both in vivo and in vitro. The same authors identified several types of chromosome segregation abnormalities, including telomere dysfunction, sister-chromatid non-disjunction, and supernumerary centrosomes in urothelial cancer cell lines. These studies strongly support the hypothesis that $\mathrm{CIN}$ is present in bladder carcinomas.

The aim of this study was to describe how CCND1 amplicons and chromosome 11 copy number heterogeneity represent in vivo features of chromosomal instability in superficial bladder carcinomas. To that end, 21 paraffin-embedded cancer tissue samples were analyzed using comparative genomic hybridization (CGH) and fluorescence in situ hybridization (FISH). In seeking a basis for the chromosomal heterogeneity, we investigated centrosome and mitotic spindle integrity by immunofluorescent staining. Our results demonstrate, for the first time, that CCND1 amplification in DM and HSR could co-exist in the same bladder tumor. A correlation between HSR fragmentation and the appearance of DMs, which were subsequently eliminated by micronuclei extrusion, was also observed. Interestingly, we found that those patients whose tumors showed CCND1 amplification in DMs had a significantly shorter overall survival rate. Finally, the correlation between chromosome instability and centrosome abnormalities showed that the coalescence of centrosomes into two functional spindle poles was common in unstable bladder tumors.

\section{Methods \\ Samples}

Twenty-one formalin-fixed and paraffin embedded bladder-tumor samples were obtained from the Fundació Puigvert and Hospital del Mar of Barcelona. Tumor stage and grade were defined according to WHO criteria [22]. All tumors were superficial or minimally invasive (nine pTa, 12 pT1). Of 21 cases, six were grade 1, eight were grade 2 and seven were grade 3 . Clinical and histopathological data are indicated in table 1 . In one patient (case U-443), the first recurrence of the tumor and the penile and inguinal lymph node metastases were also studied.

\section{Conventional comparative genomic hybridization}

For each tumor sample, DNA was extracted from four to five $10 \mu \mathrm{m}$ paraffin sections using a Qiagen Kit: QIAamp ${ }^{\oplus}$ DNA Mini Kit. Before extraction, evaluation by the pathologist determined that the proportion of tumor cells was higher than $80 \%$. The first and the last sections were stained with hematoxylin/eosin to ensure the presence of tumor in the sections series. Comparative genomic hybridization analysis was performed according to the method described by Prat et al.[3].

\section{CCND1 amplification and CIN analysis}

CIN generates intercellular numerical variation for the same chromosome within a given tumor. Fluorescence in situ hybridization analysis can be considered as a practical method to detect CIN in surgical specimens [23]. In this study, CEP 11 was used as the copy-number reference of chromosome 11 . FISH was carried out using Spectrum Orange-labeled CCND1 and Spectrum Green-labeled CEP 11 (Vysis Inc., Downers Grove, IL). Five $\mu \mathrm{m}$ sections from representative tissue blocks were used in this study. Briefly, slides were placed in the oven for $30 \mathrm{~min}$ at $65^{\circ} \mathrm{C}$ and paraffin was dissolved in Xylene. Slides were boiled in EDTA $1 \mathrm{mM}$, followed by a pepsin treatment. Post-fixation was performed in $1 \%$ formaldehyde. Co-denaturation of the slide material and the probes was carried out according to the manufacturer's instructions using a Hybrite (Vysis Inc.). Hybridization took place overnight at $37^{\circ} \mathrm{C}$ in a moist chamber. Nuclei were counterstained with 4',6-Diamidino-2-Phenylindole (DAPI, Sigma) diluted on Vectashield antifade solution at a final concentration of $125 \mathrm{ng} / \mu \mathrm{l}$. Analysis was done under a fluorescence microscope (Olympus BX-50). A minimum of 280 cells were scored in each case.

CIN index was defined as the percentage of cells not displaying the modal copy number for the studied chromosome $[16,23]$, in this case chromosome 11 . The samples 
Table 1 Patient characteristics and study results

\begin{tabular}{|c|c|c|c|c|c|c|c|c|c|c|c|c|c|c|c|c|c|}
\hline & Case & $\begin{array}{l}\text { Age/ } \\
\text { Sex }\end{array}$ & $\begin{array}{l}\text { Stage/ } \\
\text { Grade }\end{array}$ & $\begin{array}{l}\mathrm{S} / \\
\mathrm{M}\end{array}$ & CIS & $\begin{array}{c}\text { Modal } \\
\text { number } \\
\text { Chr } 11\end{array}$ & $\begin{array}{c}\text { CIN } \\
\text { index }\end{array}$ & $\begin{array}{c}\mathrm{CGH} \\
11 \mathrm{q} 13\end{array}$ & $\begin{array}{l}\text { FISH } \\
\text { CCND1 }\end{array}$ & Subpop & $\begin{array}{l}\text { SC } \\
\text { (\%) }\end{array}$ & $\begin{array}{c}\mathrm{C} \\
\text { size } \\
(\mu \mathrm{m}) \\
\end{array}$ & $A C$ & $\begin{array}{l}\text { MS } \\
\text { (\%) }\end{array}$ & $\begin{array}{l}\text { Recurrence } \\
\text { (months) }\end{array}$ & Survival & $\overline{C R D}$ \\
\hline \multirow{7}{*}{$\begin{array}{l}\text { CIN } \\
\text { negative }\end{array}$} & U-400 & $45 / 0^{\prime \prime}$ & TaG1 & $S$ & - & 2 & 17.64 & normal & normal & No & 0 & 0.8 & - & 0 & 0 & $>6$ years & No \\
\hline & U-114 & $63 / 9$ & TaG1 & $S$ & - & 2 & 20 & normal & normal & No & 3.8 & 1.10 & - & 0 & $1 ;(19)$ & $>6$ years & No \\
\hline & U-408 & $66 / \sigma^{n}$ & TaG2 & $S$ & + & 2 & 20.18 & normal & normal & No & 0 & 0.98 & - & 0 & $3 ;(4),(60),(8)$ & $>6$ years & No \\
\hline & U-814 & $68 / 0^{x}$ & $\mathrm{~T} 1 \mathrm{G} 2$ & M & - & 2 & 23.97 & gain & gain & No & 1 & 0.63 & - & 0 & $\begin{array}{c}\text { 5;(8),(15),(34), } \\
(43),(3)\end{array}$ & $>5$ years & No \\
\hline & U-373 & $52 / 9$ & TaG2 & M & - & 2 & 25.9 & normal & normal & No & 0 & 0.9 & - & 0 & $1 ;(37)$ & $>6$ years & No \\
\hline & U-906 & $58 / 0^{\pi}$ & TaG1 & $S$ & - & 2 & 25.41 & normal & normal & No & 1 & 0.81 & - & 0 & $1 ;(67)$ & $>5$ years & No \\
\hline & U-433 & $68 / 0^{\infty}$ & $\mathrm{TaG} 1$ & $S$ & + & 2 & 28.75 & normal & normal & No & $?$ & $?$ & $?$ & $?$ & $1 ;(28)$ & $>6$ years & No \\
\hline \multirow[t]{8}{*}{$\begin{array}{l}\text { Moderate } \\
\text { CIN }\end{array}$} & U-611 & $54 / 0^{\prime \prime}$ & T1G3 & $S$ & + & 2 & 33.7 & normal & normal & No & 0 & 2.04 & + & 0 & 0 & $\begin{array}{c}>42 \\
\text { months }\end{array}$ & $\overline{\mathrm{No}}$ \\
\hline & U-443 & $62 / 0^{n}$ & $\mathrm{~T} 1 \mathrm{G} 3$ & $S$ & - & 2 & 34.16 & amp & $\mathrm{HSR}$ & Yes (3) & 0 & 0.98 & - & 0 & $\begin{array}{c}3 ;(17),(13)^{*},(34) \\
*\end{array}$ & $\begin{array}{c}67 \\
\text { months }\end{array}$ & Yes \\
\hline & U-955 & $48 / 0^{\prime \prime}$ & $\mathrm{TaG} 1$ & $S$ & - & 2 & 37.91 & normal & normal & No & 0 & 0.8 & - & 0 & 0 & $>6$ years & No \\
\hline & U-089 & $45 / 0^{n}$ & TaG2 & $S$ & - & 2 & 43.33 & normal & normal & No & 5 & 1.21 & + & 0 & $2 ;(8),(13)$ & $>5$ years & No \\
\hline & U-150 & $60 / \sigma^{\prime \prime}$ & $\mathrm{T} 1 \mathrm{G} 2$ & $S$ & - & 2 & 43.51 & amp & $\begin{array}{l}\text { HSR, } \\
\text { DM }\end{array}$ & Yes (2) & 21 & 4.88 & + & 0 & $\begin{array}{c}\text { 5;(10),(17),(9), } \\
(6),(7)\end{array}$ & $\begin{array}{c}54 \\
\text { months }\end{array}$ & Yes \\
\hline & U-617 & $67 / 0^{\prime \prime}$ & TaG1 & $S$ & - & 2 & 47.5 & normal & normal & No & $?$ & $?$ & $?$ & $?$ & $2 ;(9),(11)$ & $>6$ years & No \\
\hline & U-013 & $73 / \sigma^{\infty}$ & $\mathrm{T} 1 \mathrm{G} 2$ & $S$ & + & 2 & 54.83 & normal & normal & No & 4 & 1.06 & - & 0 & 0 & $\begin{array}{c}>41 \\
\text { months }\end{array}$ & No \\
\hline & U-532 & $51 / 0^{\prime}$ & $\mathrm{T} 1 \mathrm{G} 3$ & M & + & 2 & 57.14 & normal & gain & No & 38 & 0.68 & + & 7 & 0 & $>6$ years & No \\
\hline \multirow[t]{6}{*}{ High CIN } & U-076 & $67 / 0^{\prime \prime}$ & T1G3 & $M$ & + & 2 & 60.41 & $\mathrm{amp}$ & $\begin{array}{l}\text { HSR, } \\
\text { DM }\end{array}$ & Yes (2) & 20 & 2.22 & + & 17 & $3 ;(9),(4),(10)$ & $\begin{array}{c}31 \\
\text { months }\end{array}$ & $\overline{\text { Yes }}$ \\
\hline & U-866 & $40 / \sigma^{\infty}$ & $\mathrm{T} 1 \mathrm{G} 3$ & M & + & 3 & 65.68 & normal & $\begin{array}{l}\text { gain, } \\
\text { HSR, } \\
\text { DM }\end{array}$ & Yes (3) & 0 & 5.69 & + & 0 & - & $\begin{array}{c}36 \\
\text { months }\end{array}$ & Yes \\
\hline & U-364 & $73 / 0^{\infty}$ & $\mathrm{T} 1 \mathrm{G} 3$ & $S$ & - & 2 & 67.61 & normal & $\begin{array}{l}\text { gain, } \\
\mathrm{HSR}^{1}, \\
\mathrm{HSR}^{2}\end{array}$ & Yes (3) & 27 & 2.06 & + & 17 & 0 & $\begin{array}{c}>3 \\
\text { months }\end{array}$ & No \\
\hline & U-183 & $62 / 0^{x}$ & $\mathrm{~T} 1 \mathrm{G} 3$ & M & + & 3 & 70 & normal & HSR & No & 5 & 1.18 & + & 0 & 0 & $>6$ years & No \\
\hline & U-466 & $71 / 0^{\prime \prime}$ & $\mathrm{T} 1 \mathrm{G} 2$ & $\mathrm{~S}$ & - & 4 & 70.66 & gain & gain & No & $?$ & $?$ & $?$ & $?$ & $1 ;(14)$ & $>6$ years & No \\
\hline & U-564 & $55 / 0^{\prime \prime}$ & $\mathrm{T} 1 \mathrm{G} 2$ & $S$ & - & 2 & 70.68 & loss & gain & No & 0 & 2.01 & + & 0 & $2 ;(10),(3)$ & $>6$ years & No \\
\hline
\end{tabular}

S: single, M: multiple, CIS: carcinoma in situ, CIN index: percentage of cells not displaying the modal copy number for chromosome 11, subpop: presence and number of intratumor subpopulations, defining subpopulation as a group of cells with a distinctive chromosomal alteration (numerical or structural) at a specific area on the tumor, amp: amplification, HSR: homogeneously staining region, HSR1,2: different types of homogeneously staining region, DM: double minute, SC: percentage of cells displaying supernumerary centrosomes ( $>2$ centrosomes), $C$ size: average size of centrosome, AC: presence of abnormal centrosomes (size $>2$ $\mu \mathrm{m}$ or number $>2$ in at least $5 \%$ of cells), MS: percentage of cells displaying multipolar spindle, *: metastasis, CRD: cancer related death, ?: data not available

were graded according to their CIN index, as negative CIN $(<30 \%$ of the cells with non-modal signal number), moderate $(>30 \%<60 \%$ of the cells) and high CIN $(>60 \%$ of the cells). FISH was also applied in order to analyze the amplification of CCND1 gene. Amplification was only considered when it appeared in HSR or DM forms.

\section{Immunofluorescent analysis of centrosome and mitotic spindle}

Briefly, $5 \mu \mathrm{m}$ sections from representative tissue blocks were de-paraffinized in xylene, and then rehydrated in $\mathrm{ddH}_{2} \mathrm{O}$ through graded alcohols. Slides were boiled in $1 \mathrm{mM}$ EDTA buffer ( $\mathrm{pH} .8$ ) and then were incubated overnight at $4^{\circ} \mathrm{C}$ in PBTG solution (PBS, $0.2 \%$ BSA, $0.2 \%$ gelatin, and $0.05 \%$ Tween 20 ) with primary rabbit- polyclonal $\gamma$-tubulin (T3559, Sigma-Aldrich, 1:100) and mouse-monoclonal $\alpha$-tubulin (T5168, Sigma-Aldrich, 1:200) and $\beta$-tubulin (T4026, Sigma-Aldrich, 1:200). Signal detection was performed applying fluorochromeconjugated secondary antibodies (all from Jackson ImmunoResearch Laboratories): goat anti-rabbit Cy3 (diluted 1:1,000 in PBTG) and goat anti-mouse Cy5 antibody (diluted 1:1,000 in PBTG). Secondary antibodies were incubated for $1 \mathrm{~h}$ at $37^{\circ} \mathrm{C}$. Four PBTG washes were carried out. Fixation was performed in $1 \%$ formaldehyde. Tissue sections were counterstained with DAPI and then examined under a fluorescence microscope (Olympus BX-50).

Measurements of centrosome lengths were made using the MicroMeasure v3.3 software http://www. 
biology.colostate.edu/micromeasure. The presence of supernumerary centrosomes was considered whenever the centrosome number was $\geq 3$ in at least $5 \%$ of the cells. Abnormally large centrosomes (diameter $\geq 2 \mu \mathrm{m}$ ) were indicative of centrosome clustering.

\section{Statistical analysis}

The statistical analysis of the data was carried out by using the SPSS software package (SPSS Inc; Chicago, IL, USA; Version 15.0). Overall survival was estimated with the Kaplan-Meier method. The survival curves were statistically compared by a log-rang test. Fisher's exact test was used to find associations. $\mathrm{p}<0.05$ was considered statistically significant.

\section{Results}

\section{Classification of tumors according to the CIN index}

Depending on the percentage of cells with a number of chromosome 11 different from the modal number, tumors were classified into three groups: high, moderate and negative CIN (Table 1). Samples showing an intercellular variation in the number of centromeric signals for chromosome 11 greater than $30 \%$ were deemed to have chromosomal instability. Fourteen out of 21 samples (66\%) were classified into the CIN-positive group. CIN-negative tumors showed a modal number of 2 using a centromere-specific FISH probe for chromosome 11. Only a small fraction of the tumor cells showed monosomy, while trisomy was even less frequent (Figure 1A). Within the CIN-positive group, tumors with moderate CIN levels had a modal number of 2. CIN-moderate samples showed a greater chromosome 11 copy number range than CIN-negative group, with trisomy the most frequently observed (Figure 1B). The high CIN tumors had wide-ranging chromosome 11 copy numbers (Figure $1 \mathrm{C}$ ). Monosomy was rare; the modal number was disomic in three samples, trisomic in two samples, and tetrasomic in only one sample.

There was a positive correlation between the CIN index and the tumor grade (Figure 1D). Moreover, the majority of Ta G1/G2 tumors (6/9) were included in the CIN-negative group whereas T1G3 tumors were exclusively found in high CIN (4/7) or moderate CIN (3/7) groups (Table 1).

\section{Centrosome defects and multipolar mitoses}

In seeking a basis for the observed chromosomal heterogeneity, we investigated centrosome and spindle integrity using immunofluorescent staining. Results were obtained for 18 of the 21 samples. In general, there was a positive correlation between the CIN index and centrosome abnormalities $(\mathrm{p}<0.005)$. We have used the terms supernumerary centrosomes and centrosome clustering to describe the abnormalities of the centrosomes observed in our study. Despite the fact that both terms imply the presence of extra centrosomes, we considered centrosome clustering when centrosomes could be microscopically observed as abnormally-shaped or large centrosomes and supernumerary centrosomes when they were observed individually.

Spindle errors were not present in samples with normal centrosome numbers (Figure 2A-B). In our study, supernumerary centrosomes were the most frequent aberration identified. The presence of enlarged centrosomes or shape aberrations such as string-like centrosomes (Figure 2C-E), which are indicative of centrosome clustering, was also frequently observed (Table 1). All the high CIN samples $(\mathrm{n}=5)$ showed abnormal centrosomes. Overall, supernumerary centrosomes and centrosome clustering were found in $60 \%$ and $80 \%$ of the tumors, respectively (Figure $2 \mathrm{~F}-\mathrm{J}$ ). In two samples (U076 and U-364), both centrosome alterations were concomitant. In the moderate CIN group, four out of the seven samples (57\%) showed abnormal centrosomes. Supernumerary centrosomes were found in three samples, while centrosome clustering was present in two. In one of them (U-150), both alterations were found simultaneously (Table 1). Centrosome abnormalities were absent in normal tissue adjacent to the tumor cells (Figure 2E). String-like centrosomes were found in three samples (U-150, U-866 and U-564) (Figure 2C-E). The longest centrosome was found in sample U-150 (7.33 $\mu \mathrm{m})$. These extraordinarily long centrosomes were involved in the formation of bipolar spindles (Figure 2C-D, Table 1).

Multipolar and/or pseudo-bipolar mitoses were observed in three out of six samples (50\%) with supernumerary centrosomes (Figure 2F-I). Coalescence of supernumerary centrosomes into two functional spindle poles was observed in all samples with enlarged centrosomes.

\section{CCND1 gene amplification: FISH vs. CGH}

The copy number status of CCND1 was analyzed using FISH and conventional CGH (Table 1). CCND1 amplification was identified by FISH in most of the high-CIN samples (four out of six), in $25 \%$ of the moderate-CIN samples (two out of eight) and in none of the CIN negative samples. Concordance between FISH and CGH results was observed in 16 out of 21 cases (76\%); all samples with disagreement between FISH and CGH results were CIN-positive. Sample U-532 showed no 11 q13 gain using CGH; however, $42 \%$ of cells within this sample showed five or more copies of CCND1 using FISH, even though the modal number was 2. The most divergent results were found in high-CIN tumors. Three samples (U-866, U-364 and U-183) showed CCND1 amplification using FISH, although it was not 


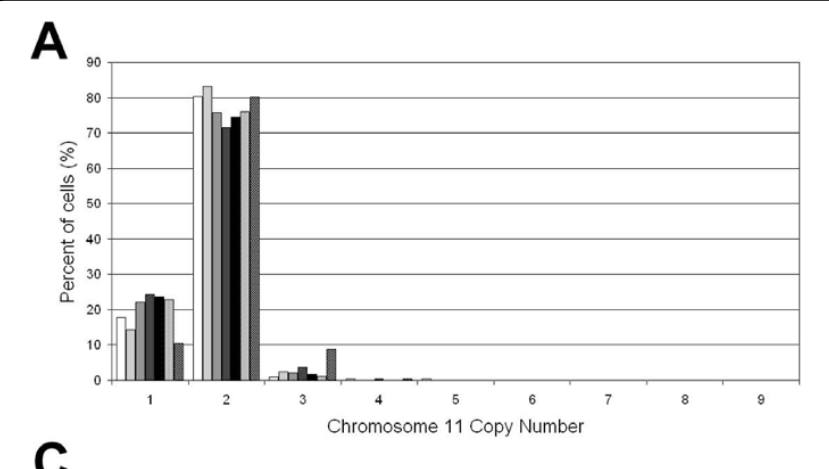

C

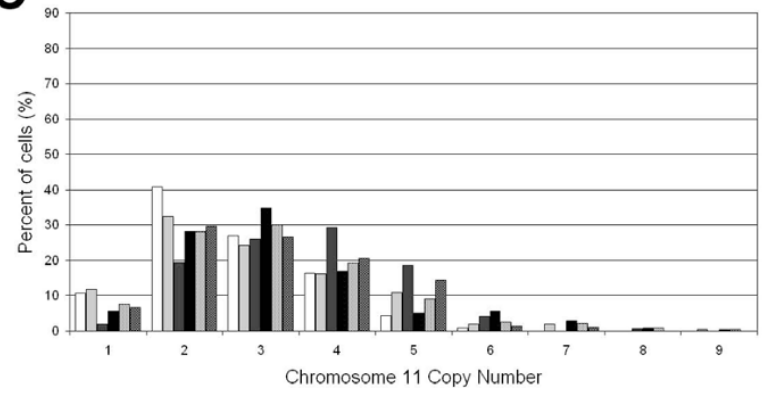

Figure 1 Chromosome 11 copy number variability. (A) Negative-CIN tumors. (B) Moderate-CIN tumors. (C) High-CIN tumors. (D) CIN index vs. tumour grade correlation.

detected using CGH. Sample U-564 showed a whole chromosome 11 loss by CGH, however more than five copies in $23 \%$ of the cells were detected using FISH. In summary, amplification of the CCND1 in DMs and/or HSRs was detected using FISH in six cases; amplification was detected using CGH only in three cases (U-443, U-150 and U-076).

\section{Intratumor cell sub-populations and CCND1 amplification behavior}

By accurately analyzing the samples showing CCND1 amplification, various cell sub-populations were detected within the tumors. A cell sub-population is defined as a group of cells with a distinctive chromosomal alteration (numerical or structural) at a specific area of the tumor. Analysis of these sub-populations provided insights into the in vivo behavior of CCND1 amplification.

Discrete cell sub-populations were found in three samples (U-076, U-866 and U-364) with a high CIN index and in two (U-443, U-150) with a moderate CIN index (Table 1). Sample U-076 had two sub-populations: one showed CCND1 amplification in HSRs, while the other showed amplification in DMs, probably due to excision from HSRs. There were also intermediate conformations, as shown in Figure 3A-H. DMs and HSRs are readily identifiable at the metaphase stage, but can also be distinguished in interphase nuclei. While HSRs are seen as a compact and distinct signal, DMs showed
B

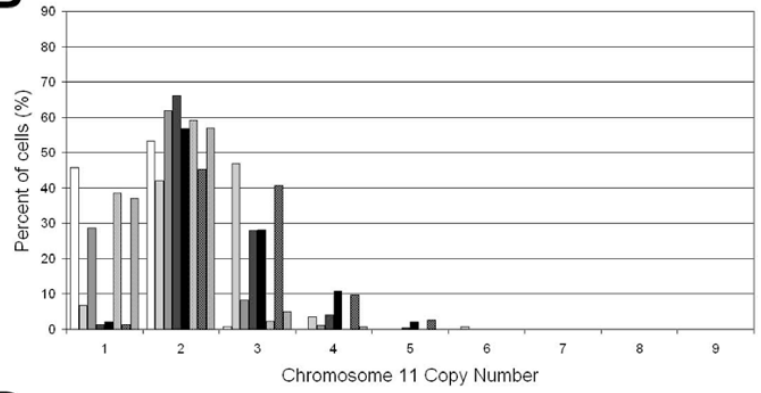

D

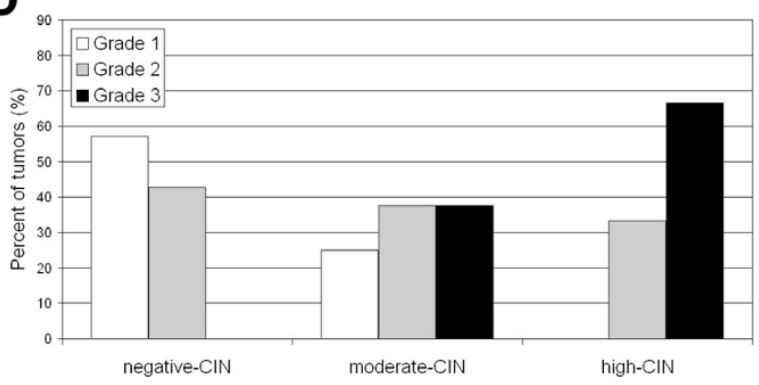

a diffuse signal. The co-existence of DMs and HSRs was also detected in two other samples (U-150 and U-866).

Sample U-364 showed a complex pattern of CCND1 amplification. Three sub-populations were detected in this sample, including one with whole chromosome gain up to nine copies (Figure 3I); two sub-populations showed CCND1 amplification as two HSRs, both of which varied significantly in terms of structure and size. One sub-population generated an amplicon with a high CCND1 copy number, which was viewed during the metaphase stage as a long CCND1-positive HSR (Figure 3J). The other sub-population showed a different amplification pattern, with fewer CCND1 copies, each of which was surrounded by some undetermined genomic material, as seen during the metaphase stage (Figure 3K).

In patient U-443, it was possible to analyze the behavior of the amplicon over a period of time. CCND1 amplification as a compact HSR was detected in the primary tumor, its recurrence and penile metastasis (after 17 and 30 months, respectively). However, diffuse HSR amplification and a small fraction of cells with DMs were observed in an inguinal lymph node metastasis detected 34 months after the penile metastasis. These results suggest that HSRs could remain stable during long periods before giving rise to DMs during a latemetastasis. (The patient died three months following the metastasis). 

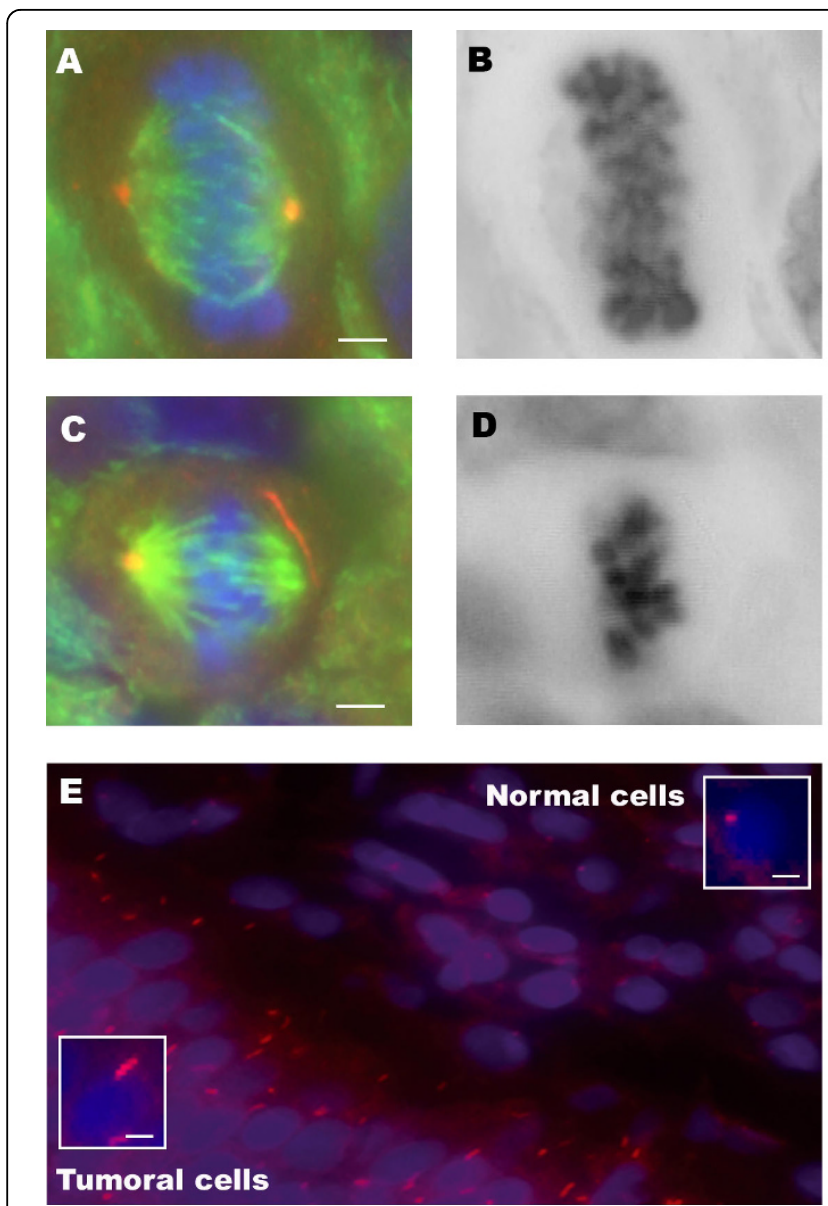
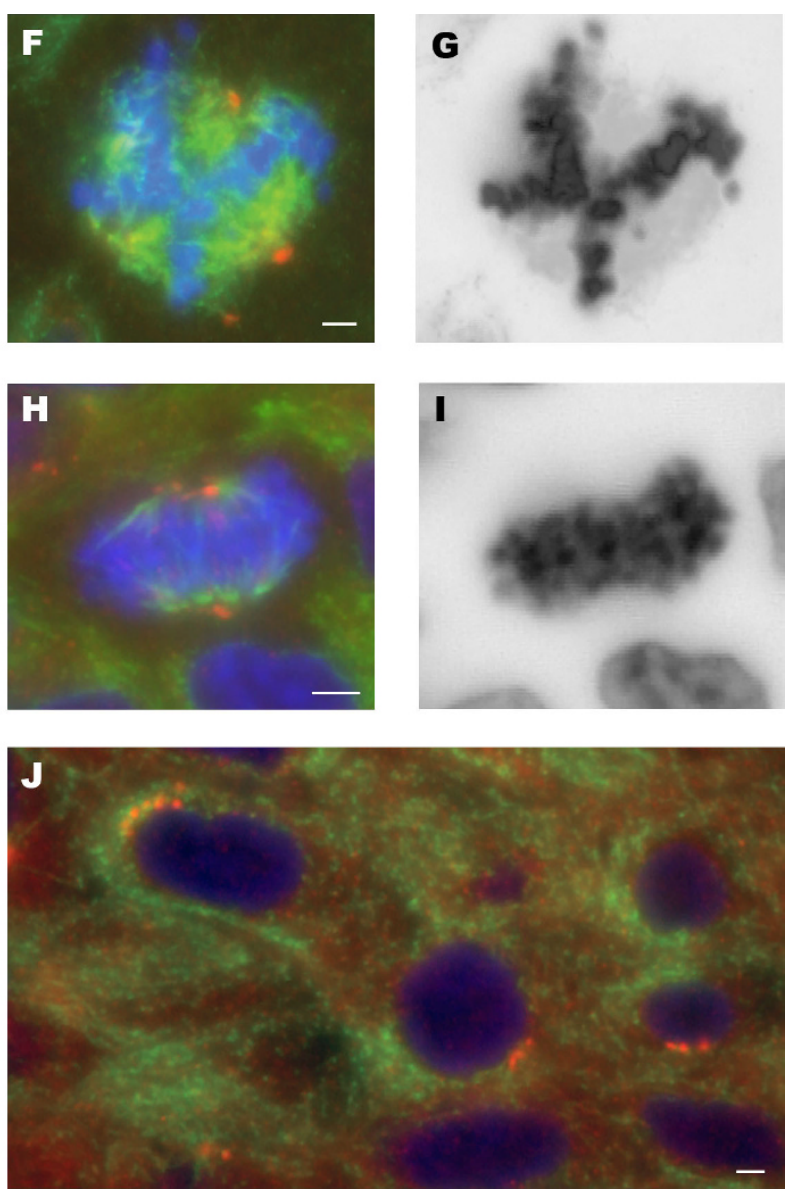

Figure 2 Centrosome abnormalities. Immunolabeling was performed for $\boldsymbol{\gamma}$-tubulin (red) and $\boldsymbol{\alpha}$ and $\beta$-tubulin (green). DNA staining was performed with DAPI (blue). Black and white images correspond to DAPI reverse staining. (A-B) Normal/bipolar spindle. (C-D) Bipolar metaphase with string-like centrosome. (E) Tumour cells with abnormally long centrosomes, close to the adjacent normal urothelium. (F-G) Multipolar spindle. (H-I) Pseudo-bipolar metaphase. (J) Tumour cells with supernumerary centrosomes. Scale bar, 3 um.

It is noteworthy that those patients, whose primary tumors showed DMs had cancer-related deaths. The Kaplan-Meier analysis showed that these patients (U150, U-76 and U-866) had a significantly shorter overall survival rate than patients without DMs in their primary tumors (including U-443) ( $\mathrm{p}<0.001)$. Therefore we concluded that high heterogeneity samples showed different populations with amplification of CCND1 and it correlates with clinical features.

\section{DMs distribution on the metaphase plate, micronuclei,}

\section{internuclear bridges and nuclear blebs}

This analysis was carried out on samples showing CCND1 gene amplification in DMs (samples U-150, U076 and U-866) (Table 2). DMs containing CCND1 were predominantly located in the peripheral region of the metaphase plate (Figure 3L-O) (Table 2). Metaphases were analyzed in paraffin-embedded tissue sections, allowing the identification of DMs containing
CCND1 non-randomly located at the periphery during metaphase in bladder primary tumors.

All samples with DMs showed nuclear blebs and micronuclei, whereas the samples without DMs did not. The size of the micronuclei varied from $5-30 \%$ of nuclear volume. The number of micronuclei per 100 cells varied from 10-13 (Table 2). In samples U-150 and U-076, a significant percentage of micronuclei were CCND1-positive (45\% and 40\% respectively) (Figure 3PQ). Approximately $2 \%$ of the micronuclei in these samples were positive for chromosome 11 centromere. In sample U-866, there were 10 micronuclei per 100 cells, being $24 \%$ of them CCND1-positive. This tumor had a higher proportion of micronuclei positive for centromere $11(24 \%)$, indicating a very high level of aneuploidy, compared with the previous two samples (U-076 and U-150). The complete removal of DMs by micronucleus extrusion, giving rise to cells with two or three CCND1 gene copies, was also observed in a small 

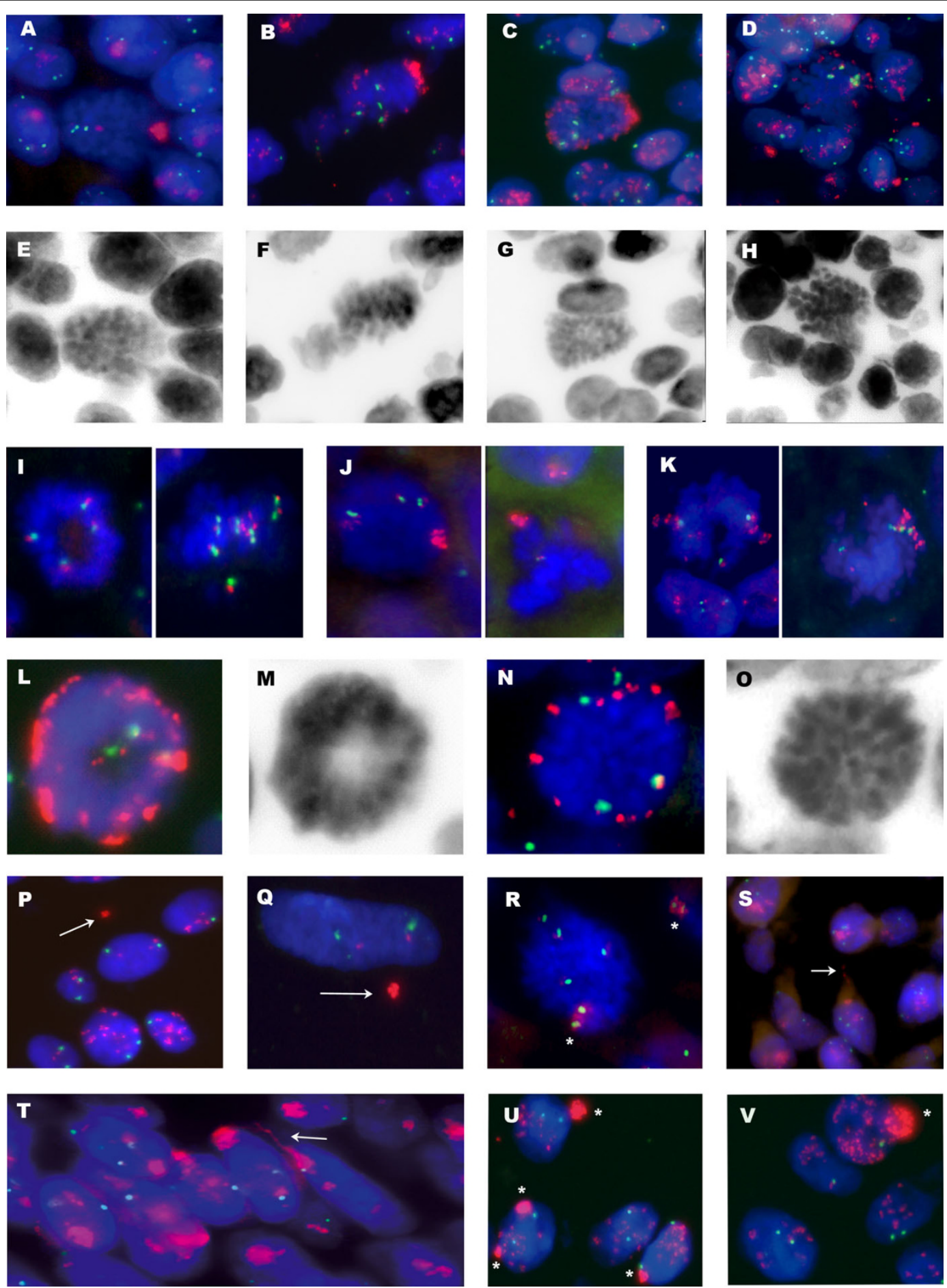

Figure 3 CCND1 amplification behaviour in bladder tumors. FISH identification of chromosome 11 centromere (green) and CCND1 gene (red) in paraffin-embedded tumors. DNA staining was performed with DAPI (blue). Black and white images correspond to DAPI reverse staining. $(\mathrm{A}-\mathrm{H})$ Metaphasic cells showing the proposed sequence of 11q13 amplicon fragmentation from HSRs to DMs. (I-K) Sample U-364 showed a complex pattern of CCND1 amplification. Three sub-populations were detected in this sample. (I) Sub-population with gain of whole

chromosome 11. (J) Sub-population containing HSR with high-level amplification of CCND1 (K) Sub-population containing amplification of CCND1 and undetermined flanking material in HSR. (L-O) Peripheral location of DMs in metaphasic cells. (P-Q) CCND1-positive micronuclei, see arrows. In $\mathrm{Q}$, note the elimination in the micronucleus of whole CCND1 copies, except those attached to the centromere. (R) Metaphasic cells containing a dicentric chromosome with two centromeric signals of chromosome 11 and CCND1 amplification, see asterisks. (S and T) CCND1 with HSRs appears to be forming internuclear bridges, see arrows. ( $U$ and $V)$ Nuclear blebs as nuclear protrusions with high CCND1 signal. 
Table 2 DM localization on metaphase plate and micronuclei frequencies

\begin{tabular}{|c|c|c|c|c|c|c|c|c|}
\hline \multirow[b]{2}{*}{ Sample } & \multicolumn{2}{|c|}{$\begin{array}{c}\text { Peripheral localization of } \\
\text { DMs }\end{array}$} & \multicolumn{2}{|c|}{$\begin{array}{c}\text { CCND1 Positive } \\
\text { MN }\end{array}$} & \multicolumn{2}{|c|}{$\begin{array}{c}\text { CEP11 positive } \\
\text { MN }\end{array}$} & \multicolumn{2}{|c|}{ Total MN } \\
\hline & $\begin{array}{c}\text { per } \\
\text { metaphase }\end{array}$ & $\begin{array}{c}\text { per } 100 \\
\text { metaphase }\end{array}$ & $\begin{array}{c}\text { per } \\
\text { nuclei }\end{array}$ & $\begin{array}{c}\text { per } 100 \\
\text { nuclei }\end{array}$ & $\begin{array}{c}\text { per } \\
\text { nuclei }\end{array}$ & $\begin{array}{c}\text { per } 100 \\
\text { nuclei }\end{array}$ & $\begin{array}{c}\text { per } \\
\text { nuclei }\end{array}$ & $\begin{array}{c}\text { per } 100 \\
\text { nuclei }\end{array}$ \\
\hline U-150 & $22 / 25$ & $88.00 \%$ & $28 / 472$ & $5.93 \%$ & $1 / 472$ & $0.21 \%$ & $62 / 472$ & $13.14 \%$ \\
\hline U-076 & $27 / 36$ & $75.00 \%$ & $19 / 477$ & $3.98 \%$ & $1 / 477$ & $0.21 \%$ & $48 / 477$ & $10.06 \%$ \\
\hline U-866 & $15 / 20$ & $75.00 \%$ & $10 / 412$ & $2.43 \%$ & $10 / 412$ & $2.43 \%$ & $42 / 412$ & $10.19 \%$ \\
\hline
\end{tabular}

DM: Double minute, MN: Miclonuclei, CEP: Centromere

number of cells (Figure 3P-Q). The presence of metaphase dicentric chromosomes, internuclear bridges, and nuclear blebs positive for the CCND1 amplification demonstrated the ongoing chromosomal instability observed in high CIN bladder primary tumors (Figure 3R-V).

\section{Discussion}

In the present study, the gene copy number variation analysis of CCND1 in formalin fixed paraffin embedded tissue sections revealed a complex and unprecedented pattern of cellular behavior in non-muscle invasive bladder tumors. Our results suggested that copy number changes of CCND1 could be used as a biomarker to detect chromosome instability in bladder cancer. Bladder tumors were classified according to the CIN index, and we have shown a positive correlation between high heterogeneity, centrosome abnormalities and CCND1 gene amplification.

A positive correlation between the level of chromosomal instability and the tumor grade was identified; this phenomenon was previously described in bladder cancer [16]. Focusing exclusively on chromosome 11, the present study classifies the majority of Ta tumors as stable (CIN-negative group). These results are in agreement with the 2004 WHO classification that distinguishes two different entities in non-muscle invasive bladder tumors: one (Ta low-grade G1/G2) genetically stable in which gene amplifications are rare, and the other (T1 highgrade) with a high degree of genetic instability including high level amplifications [24]. Despite the low number of samples analyzed, it is remarkable that our classification of tumors according to their CIN index included all T1G3 samples in the CIN-positive group. CIN-negative group was just composed of grade 1 and grade 2 tumors, being all but one Ta. CCND1 amplification was exclusively observed in $\mathrm{CIN}$-positive samples, suggesting that CCND1 might be involved in the generation of centrosomal abnormalities [25]. Moreover, we showed amplification of CCND1 as DMs in three CIN-positive samples. To our knowledge, this is the first report in the literature to show genomic amplification of CCND1 as DMs in bladder tumors.
The differences between FISH and metaphase CGH results for the CIN-positive samples highlight intratumoral heterogeneity. CGH detected the dominant genomic alterations present in at least some $60 \%$ of the tumor population [26]; however, it did not detect either the alterations that appear in a small number of cells or ongoing chromosomal instability. The association of DMs, centrosome aberrations and intercellular CIN observed in this study may indicate that the CIN phenotype does not become the major clonal population in bladder cancer.

As expected, centrosome amplification is correlated with CIN. Approximately, 75\% (9/12) of CIN-positive samples and none of the CIN-negative samples showed centrosomal abnormalities. During the analysis of metaphase figures, multipolar and pseudo-bipolar spindles were identified in some CIN-positive tumors with supernumerary centrosomes. The presence of extra centrosomes within tumor cells might be deleterious as multipolar mitosis may generate sufficient high levels of aneuploidy to compromise cell viability. Several cancer cell lines overcome this problem by clustering their extra centrosomes at the two poles of the spindle, thus ensuring bipolar chromosome segregation [27-29]. This phenomenon was observed in some samples in the present study showing abnormal large centrosomes and bipolar spindles, what confirms that centrosome clustering occurs in bladder cancer. It is interesting to note that bipolar spindles were also observed in three CINpositive samples displaying a string-like centrosome similar to what was observed by Pihan et al. [30] in malignant tumors and tumor-derived cell lines.

In addition, the high chromosomal instability observed in our samples with centrosome clustering suggests that other factors might cause chromosomal instability. In fact, chromosome lagging, defined as a delayed movement of one chromatide in anaphase, was observed when anaphasic cells were studied. This is consistent with studies carried out by Thompson and Compton [31] on human cell lines, where the authors identified defective kinetochore-spindle attachments leading to anaphase lagging as a cause of chromosome missegregation. Recently, Ganem et al. [32] demonstrated that 
extra centrosomes alone are sufficient to promote chromosome missegregation during bipolar cell division. According to these authors, cells passing a transient multipolar spindle intermediate accumulate merotelic kinetochore-spindle attachment errors before centrosome clustering and anaphase.

DNA sequence amplification is one of the hallmarks of genomic instability in cancer. The target genes driving the 11q13 amplicon have been extensively reported, and at least four cores of amplification have been established in breast cancer [33,34]. However, the evolution of this amplicon in tumor cells remains unclear. The $11 q 13$ amplicon is usually located in the same chromosomal region as the amplified target gene [7,8,35,36]. In our study, HSRs were usually located in the same chromosomal region as the amplified target genes, thus strongly supporting the hypothesis that the 11q13 amplicon is of intrachromosomal origin [8]. The presence of dicentric chromosomes and anaphase bridges in cell populations undergoing amplification is consistent with the role of the breakage-fusion-bridge (BFB) cycle in explaining intrachromosomal amplifications [37]. In the present study, the HSR-bearing chromosome 11 was often observed to be involved in nucleoplasmatic bridges and dicentric chromosomes.

Nevertheless, several mechanisms for the genesis of extrachromosomal amplifications (i.e., DMs) have been proposed [38]. A yeast model system was used to demonstrate that hairpin-capped double-strand breaks occurring at the location of human Alu-quasipalindromes trigger both DM and HSR gene amplification. According to this model, the nature of the amplicons depends on the chromosomal location of the amplified gene relative to double-strand break formation [39]. Within our sample set, the co-existence of CCND1 amplification in DMs and HSR is noteworthy. In tumor samples with both types of amplification, metaphasic cells with both HSR and DMs were observed in the transition zone between the HSR and DM carrier cell sub-populations. These data demonstrate a striking correlation between the presence of DMs and the observed fragmentation of HSR, thus suggesting a possible mechanism for excising amplified sequences in HSRs, giving rise to DMs. A similar phenomenon has been described in human cell lines with dihydrofolate-resistance gene amplification [40,41]. Our findings strongly suggest that the same mechanism operates in tumor cells in vivo. Moreover, as seen in patient U-443, fragmentation of the HSR might occur in a metastatic form, after remaining stable for a long period of time in the primary tumor.

All samples with DMs also exhibited micronuclei; approximately $50 \%$ of them were CCND1-positive. The fact that the CCND1 signal was not present in the remaining $50 \%$ of the micronuclei indicates that other genomic regions were being actively eliminated from these cells. These findings suggest that micronuclei extrusion could induce rapid and dramatic changes, not only in the CCND1 gene with DMs, but also in other acentric fragments or even affecting whole chromosome copy numbers, therefore exacerbating genomic instability. The removal of amplified CCND1 sequences by micronuclei extrusion in bladder tumor cells was consistent with results reported by Valent et al. [42] regarding DMs containing MYCN neuroblastoma. Furthermore, in the present study, some cells showed one to three copies of the CCND1 on chromosome 11, but with an adjacent CCND1-positive micronucleus, suggesting that in some cells the normal copy number for this gene is restored by DMs extrusion.

It is known that centrosome amplification is a source of CIN, as are chromosomal lagging and micronuclei formation. Centrosome clustering partially reduces chromosomal instability [28], and increases cell viability by avoiding multipolar mitosis. Our observations that centrosome clustering is a common feature of chromosomally unstable bladder tumors, and the appearance of new drugs that specifically target centrosome clustering, such as griseofulvin [43], highlights the importance of further studying the role of centrosome abnormalities in bladder cancer.

\section{Conclusions}

The present study describes the in vivo behavior of CCND1 amplification in chromosome unstable T1 bladder tumors. We also demonstrate that the coalescence of centrosomes into two functional spindle poles is a common feature of these tumors.

Our study is the first report in the literature regarding the simultaneous CCND1 amplification in DM and HSR in bladder cancer cells. Our findings suggest a striking correlation between HSR fragmentation and the appearance of DMs which subsequently are removed by micronuclei extrusion. Of interest, we found that only those patients whose tumors showed CCND1 amplification in DMs had a significantly shorter overall survival rate. Further studies in a larger sample size should be necessary in order to confirm our results.

Coalescence of supernumerary centrosomes was observed in $80 \%$ of the most unstable tumors, highlighting the importance of this phenomenon in bladder cancer.

Data presented here contribute to the understanding of the in vivo chromosome behavior of bladder tumor cells, and show how its complexity could be analyzed by FISH on paraffin embedded tumors as if snapshots of what occurs in the tumor at the time of surgical removal had been taken. 


\section{List of abbreviations}

CIN: chromosome instability; CCND1: cyclin D1 gene; DM: double-minute; HSR: homogeneously staining region; CGH: comparative genomic hybridization; FISH: fluorescence in situ hybridization.

\section{Acknowledgements \\ The work has been supported by ISCIII: EPICUR-Red (FIS G03/174), SAF2007 64167 and RD06/0020/1020. Javier del Rey was a fellow of Generalitat de Catalunya and is supported by RD06/0020/1020. We thank The Language Advisory \& Translation Unit at The Universitat Autònoma de Barcelona.}

\section{Author details}

'Departament de Biologia Cellular Fisiologia i Immunologia, Institut de Biotecnologia i de Biomedicina, Universitat Autònoma de Barcelona, 08193, Bellaterra, Spain. ${ }^{2}$ Departament de Patologia, Hospital del Mar, IMAS, Universitat Pompeu Fabra, Passeig Marítim 25-29, Barcelona 08003, Spain. ${ }^{3}$ Departament d'Urologia, Hospital del Mar, IMAS UAB, Passeig Marítim 25-29 08003, Barcelona, Spain. ${ }^{4}$ Departament de Patologia, Fundació Puigvert, Universitat Autònoma de Barcelona, Cartagena 340-350, 08025 Barcelona, Spain. ${ }^{5}$ Genetics Branch, Center for Cancer Research, National Cancer Institute/NIH, 50 South Drive, Bethesda, MD 20892, USA.

\section{Authors' contributions}

$J d R$ carried out all the experimental studies, participated in design of the study, analysis and interpretation of data and drafted and revised the manuscript. EP participated in $\mathrm{CGH}$ analysis and helped to draft the manuscript. IP participated in FISH analysis. JL, AG and FA were involved in acquisition and interpretation of data. JC was involved in drafting and revising the manuscript. RM conceived of the study and participated in its design and coordination, was involved in drafting and revising the manuscript. All authors read and approved the final manuscript.

\section{Competing interests}

The authors declare that they have no competing interests.

Received: 24 November 2009 Accepted: 11 June 2010

Published: 11 June 2010

\section{References}

1. Hanahan D, Weinberg RA: The hallmarks of cancer. Cell 2000, 100:57-70.

2. Fadl-Elmula I: Chromosomal changes in uroepithelial carcinomas. Cell Chromosome 2005, 4:1

3. Prat E, Bernues M, Caballin MR, Egozcue J, Gelabert A, Miro R: Detection of chromosomal imbalances in papillary bladder tumors by comparative genomic hybridization. Urology 2001, 57:986-992.

4. Bringuier PP, Tamimi Y, Schuuring E, Schalken J: Expression of cyclin D1 and EMS1 in bladder tumours; relationship with chromosome 11q13 amplification. Oncogene 1996, 12:1747-1753.

5. Ewen ME, Lamb J: The activities of cyclin D1 that drive tumorigenesis. Trends Mol Med 2004, 10:158-162.

6. Zaharieva BM, Simon R, Diener PA, Ackermann D, Maurer R, Alund G, Knonagel $H$, Rist M, Wilber K, Hering F, et al: High-throughput tissue microarray analysis of 11q13 gene amplification (CCND1, FGF3, FGF4, EMS1) in urinary bladder cancer. J Pathol 2003, 201:603-608.

7. Schwab M: Amplification of oncogenes in human cancer cells. Bioessays 1998, 20:473-479.

8. Roelofs H, Schuuring E, Wiegant J, Michalides R, Giphart-Gassler M: Amplification of the 11 q13 region in human carcinoma cell lines: a mechanistic view. Genes Chromosomes Cancer 1993, 7:74-84.

9. Moreau LA, McGrady P, London WB, Shimada H, Cohn SL, Maris JM, Diller L, Look AT, George RE: Does MYCN amplification manifested as homogeneously staining regions at diagnosis predict a worse outcome in children with neuroblastoma? A Children's Oncology Group study. Clin Cancer Res 2006, 12:5693-5697.

10. O'Neill S, Ekstrom L, Lastowska M, Roberts P, Brodeur GM, Kees UR, Schwab M, Bown N: MYCN amplification and $17 q$ in neuroblastoma: evidence for structural association. Genes Chromosomes Cancer 2001, 30:87-90.

11. Lengauer C: Aneuploidy and genetic instability in cancer. Semin Cancer Biol 2005, 15:1

12. Rajagopalan H, Lengauer C: Aneuploidy and cancer. Nature 2004, 432:338-341

13. Draviam VM, Xie S, Sorger PK: Chromosome segregation and genomic stability. Curr Opin Genet Dev 2004, 14:120-125.

14. Andersen SS: Molecular characteristics of the centrosome. Int Rev Cytol 1999, 187:51-109.

15. Pihan GA, Purohit A, Wallace J, Knecht H, Woda B, Quesenberry P Doxsey SJ: Centrosome defects and genetic instability in malignant tumors. Cancer Res 1998, 58:3974-3985.

16. Yamamoto Y, Matsuyama H, Kawauchi S, Furuya T, Liu XP, Ikemoto K, Oga A, Naito K, Sasaki K: Biological characteristics in bladder cancer depend on the type of genetic instability. Clin Cancer Res 2006, 12:2752-2758.

17. Basto R, Brunk K, Vinadogrova T, Peel N, Franz A, Khodjakov A, Raff JW: Centrosome amplification can initiate tumorigenesis in flies. Cell 2008, 133:1032-1042.

18. Jiang F, Caraway NP, Sabichi AL, Zhang HZ, Ruitrok A, Grossman HB, Gu J, Lerner SP, Lippman S, Katz RL: Centrosomal abnormality is common in and a potential biomarker for bladder cancer. Int J Cancer 2003, 106:661-665

19. Kawamura K, Izumi H, Ma Z, Ikeda R, Moriyama M, Tanaka T, Nojima T, Levin LS, Fujikawa-Yamamoto K, Suzuki K, et al: Induction of centrosome amplification and chromosome instability in human bladder cancer cells by p53 mutation and cyclin E overexpression. Cancer Res 2004, 64:4800-4809.

20. Kawamura K, Moriyama M, Shiba N, Ozaki M, Tanaka T, Nojima T, FujikawaYamamoto K, Ikeda R, Suzuki K: Centrosome hyperamplification and chromosomal instability in bladder cancer. Eur Urol 2003, 43:505-515.

21. Jin $Y$, Stewenius $Y$, Lindgren $D$, Frigyesi $A$, Calcagnile $O$, Jonson $T$, Edqvist $A$, Larsson N, Lundberg LM, Chebil G, et al: Distinct mitotic segregation errors mediate chromosomal instability in aggressive urothelial cancers. Clin Cancer Res 2007, 13:1703-1712.

22. Epstein Jl, Amin MB, Reuter VR, Mostofi FK: The World Health Organization/ International Society of Urological Pathology consensus classification of urothelial (transitional cell) neoplasms of the urinary bladder. Bladder Consensus Conference Committee. Am J Surg Pathol 1998, 22:1435-1448.

23. Nakamura H, Saji H, Idiris A, Kawasaki N, Hosaka M, Ogata A, Saijo T, Kato H: Chromosomal instability detected by fluorescence in situ hybridization in surgical specimens of non-small cell lung cancer is associated with poor survival. Clin Cancer Res 2003, 9:2294-2299.

24. Sauter G, Algaba F, Amin M, Busch C, Cheville J, Gasser T, Grignon DJ, Hostädter F, Lopez-Beltran A, Epstein Il: Non Invasive urothelial neoplasias. WHO classification of non invasive papillary urothelial tumors. World Health organisation classification of tumors. Pathology and gentics: tumors of the urinary sistem and male genital organs Lyon: IARCEble JN, Sauter G, Epstein J, Sesterhenn I 2004

25. Nelsen CJ, Kuriyama R, Hirsch B, Negron VC, Lingle WL, Goggin MM, Stanley MW, Albrecht JH: Short term cyclin D1 overexpression induces centrosome amplification, mitotic spindle abnormalities, and aneuploidy. J Biol Chem 2005, 280:768-776.

26. Kallioniemi OP, Kallioniemi A, Piper J, Isola J, Waldman FM, Gray JW, Pinkel D: Optimizing comparative genomic hybridization for analysis of DNA sequence copy number changes in solid tumors. Genes Chromosomes Cancer 1994, 10:231-243.

27. Quintyne NJ, Reing JE, Hoffelder DR, Gollin SM, Saunders WS: Spindle multipolarity is prevented by centrosomal clustering. Science 2005 , 307:127-129.

28. Chandhok NS, Pellman D: A little CIN may cost a lot: revisiting aneuploidy and cancer. Curr Opin Genet Dev 2009, 19:74-81.

29. Gergely F, Basto R: Multiple centrosomes: together they stand, divided they fall. Genes Dev 2008, 22:2291-2296.

30. Pihan GA, Wallace J, Zhou Y, Doxsey SJ: Centrosome abnormalities and chromosome instability occur together in pre-invasive carcinomas. Cancer Res 2003, 63:1398-1404.

31. Thompson SL, Compton DA: Examining the link between chromosomal instability and aneuploidy in human cells. J Cell Biol 2008, 180:665-672. 
32. Ganem NJ, Godinho SA, Pellman D: A mechanism linking extra centrosomes to chromosomal instability. Nature 2009, 460:278-282.

33. Hui R, Campbell DH, Lee CS, McCaul K, Horsfall DJ, Musgrove EA, Daly RJ, Seshadri R, Sutherland RL: EMS1 amplification can occur independently of CCND1 or INT-2 amplification at 11q13 and may identify different phenotypes in primary breast cancer. Oncogene 1997, 15:1617-1623.

34. Ormandy CJ, Musgrove EA, Hui R, Daly RJ, Sutherland RL: Cyclin D1, EMS1 and 11q13 amplification in breast cancer. Breast Cancer Res Treat 2003, 78:323-335.

35. Jin C, Jin Y, Gisselsson D, Wennerberg J, Wah TS, Stromback B, Kwong YL, Mertens F: Molecular cytogenetic characterization of the $11 \mathrm{q} 13$ amplicon in head and neck squamous cell carcinoma. Cytogenet Genome Res 2006, 115:99-106.

36. Jin Y, Hoglund M, Jin C, Martins C, Wennerberg J, Akervall J, Mandahl N, Mitelman F, Mertens F: FISH characterization of head and neck carcinomas reveals that amplification of band $11 q 13$ is associated with deletion of distal 11q. Genes Chromosomes Cancer 1998, 22:312-320.

37. Debatisse M, Coquelle A, Toledo F, Buttin G: Gene amplification mechanisms: the role of fragile sites. Recent Results Cancer Res 1998, 154:216-226.

38. Kuttler F, Mai S: Formation of non-random extrachromosomal elements during development, differentiation and oncogenesis. Semin Cancer Biol 2007, 17:56-64.

39. Narayanan V, Mieczkowski PA, Kim HM, Petes TD, Lobachev KS: The pattern of gene amplification is determined by the chromosomal location of hairpin-capped breaks. Cell 2006, 125:1283-1296.

40. Singer MJ, Mesner LD, Friedman CL, Trask BJ, Hamlin JL: Amplification of the human dihydrofolate reductase gene via double minutes is initiated by chromosome breaks. Proc Natl Acad Sci USA 2000, 97:7921-7926.

41. Morales C, Garcia MJ, Ribas M, Miro R, Munoz M, Caldas C, Peinado MA: Dihydrofolate reductase amplification and sensitization to methotrexate of methotrexate-resistant colon cancer cells. Mol Cancer Ther 2009, 8:424-432.

42. Valent A, Benard J, Clausse B, Barrois M, Valteau-Couanet D, TerrierLacombe MJ, Spengler B, Bernheim A: In vivo elimination of acentric double minutes containing amplified MYCN from neuroblastoma tumor cells through the formation of micronuclei. Am J Pathol 2001, 158:1579-1584.

43. Rebacz B, Larsen TO, Clausen MH, Ronnest MH, Loffler $H, H o$ AD, Kramer A: Identification of griseofulvin as an inhibitor of centrosomal clustering in a phenotype-based screen. Cancer Res 2007, 67:6342-6350.

\section{Pre-publication history}

The pre-publication history for this paper can be accessed here: http://www.biomedcentral.com/1471-2407/10/280/prepub

doi:10.1186/1471-2407-10-280

Cite this article as: del Rey et al:: Centrosome clustering and cyclin D1 gene amplification in double minutes are common events in chromosomal unstable bladder tumors. BMC Cancer 2010 10:280.

\section{Submit your next manuscript to BioMed Central and take full advantage of:}

- Convenient online submission

- Thorough peer review

- No space constraints or color figure charges

- Immediate publication on acceptance

- Inclusion in PubMed, CAS, Scopus and Google Scholar

- Research which is freely available for redistribution

Submit your manuscript at www.biomedcentral.com/submit
Biomed Central 